\title{
A STUDY OF THE CONCEPT OF PARAMETRIC MODELING OF CONSTRUCTION OBJECTS
}

\author{
Kateryna I. Kyivska \\ Kyiv National University of Construction and Architecture, Kyiv, Ukraine. \\ Svitlana V. Tsiutsiura \\ Kyiv National University of Construction and Architecture, Kyiv, Ukraine. \\ Mikola I. Tsiutsiura \\ Kyiv National University of Construction and Architecture, Kyiv, Ukraine.
}

\section{Olena V. Kryvoruchko}

Kyiv National University of Trade and Economics, Kyiv, Ukraine.

\section{Andrii V. Yerukaiev}

Kyiv National University of Construction and Architecture, Kyiv, Ukraine.

\section{Vladyslav V. Hots}

Kyiv National University of Construction and Architecture, Kyiv, Ukraine.

\begin{abstract}
Integration of information models between different software systems is an urgent task. There are a large number of CAD systems that cover more than $90 \%$ of the design tasks, but the mechanism for transferring information between these programs has not yet been worked out. Despite the use of common data integration formats (such as IFC, $X M L, D X F, D W G, P D F), C A D$ model elements are represented using various indicators and characteristics. This leads to a partial loss of information on objects. Integration of the model in an incomplete form and filling in the missing parameters manually takes a lot of time and is not effective. To solve this problem, research was carried out, the result of which was the generalization and structuring of the parameters of the elements of information models of building objects. This allows you to solve the problem of heterogeneity of information about the model coming from different sources.
\end{abstract}

Keywords: Computer models, information modeling, design technologies, BIMtechnology. 
Cite this Article: Kateryna I. Kyivska, Svitlana V. Tsiutsiura, Mikola I. Tsiutsiura, Olena V. Kryvoruchko Andrii V. Yerukaiev and Vladyslav V. Hots, a Study of the Concept of Parametric Modeling of Construction Objects, International Journal of Advanced Research in Engineering and Technology, 10(2), 2019, pp. 636-646. $\mathrm{http}: / /$ iaeme.com/Home/issue/IJARET?Volume $=10 \&$ Issue $=2$

\section{INTRODUCTION}

The development of modern information technology has led to the emergence of a new direction in architectural and construction design, namely the creation of a model of a building that covers all information about the future (or existing) object from the main idea of its creation until the demolition - the BIM-technology (Building Information Model).

In Ukraine, the development and implementation of BIM technology is slow enough. There are no state programs for the development of standards and requirements for the formation of information models of buildings. At the moment, we are on the way to developing a new approach to the concept of automated design in construction, which leads to the existence of a number of problems associated with the creation of information models of construction sites, their content, integration and support. An urgent task today is to structure the parameters of elements of an information model of a building, which is based on BIM-technology.

Since the only developed and accepted standards for BIM technology do not exist, and there are many problems with their use, the work on creating an information model of building objects and parametric modeling is carried out at once in many directions: the application of cloud-based BIM-technologies in the building sector [1]; methods and means of implementing BIM-technologies in the design practice [2-3]; possibilities of multilevel integration of information models between different $\mathrm{CAD}[4,6]$; study on the application of BIM technology for building certification based on standards for technical construction requirements [7].

One of the important problems of using the concept of BIM technology, to date, is the large number of CAD, which, on the one hand, covers part of the tasks of automated design, on the other hand, the mechanism for the transfer of information between these programs is significantly limited, since despite the generally accepted formats of data models, which support most of these programs, each of them contains a different set of information about the construction object, which leads to a partial loss of information when importing or exporting models. The variant of transmission of the model in a trimmed form and filling the missing parameters is rather laborious.

This problem still remains unresolved, as CAD developers focus on developing their own programs, and practically do not deal with the establishment of interconnections with competing ones. Given this and the heterogeneity of information that is received and processed in modern $\mathrm{CAD}$, there is a need to structure the parameters of information models to create from them a single informative generalized model.

Almost all modern automated design systems support the parameterization function. But each of them implements this mechanism in different ways. In most cases, creation of, for example, parametric drawings is not possible without the creation of a 3D model. And this is a significant problem, since the development of generalized parameterizations mechanism enables to integrate (Fig.1) information models of construction objects between software tools of different purposes without loss of information.

Using the concept of parameterizations, the user will be able to either enter the numeric or textual value of any parameter, or use a variable or an expression that depends on other variables. It allows you to associate the values among themselves, to count them by formulas, depending on the input parameters, to change from the outside (read from the file, set in other 
Kateryna I. Kyivska, Svitlana V. Tsiutsiura, Mikola I. Tsiutsiura, Olena V. Kryvoruchko Andrii V. Yerukaiev and Vladyslav V. Hots

programs). Variables, in turn, allow you to get the values of the required parameters in any elements of the information model (to determine the thickness, length of the element), to pass the necessary to other related elements [8].

In a generalized form, the information that can be received in the database of the information model of construction objects from different software, is presented in Table 1. [9].

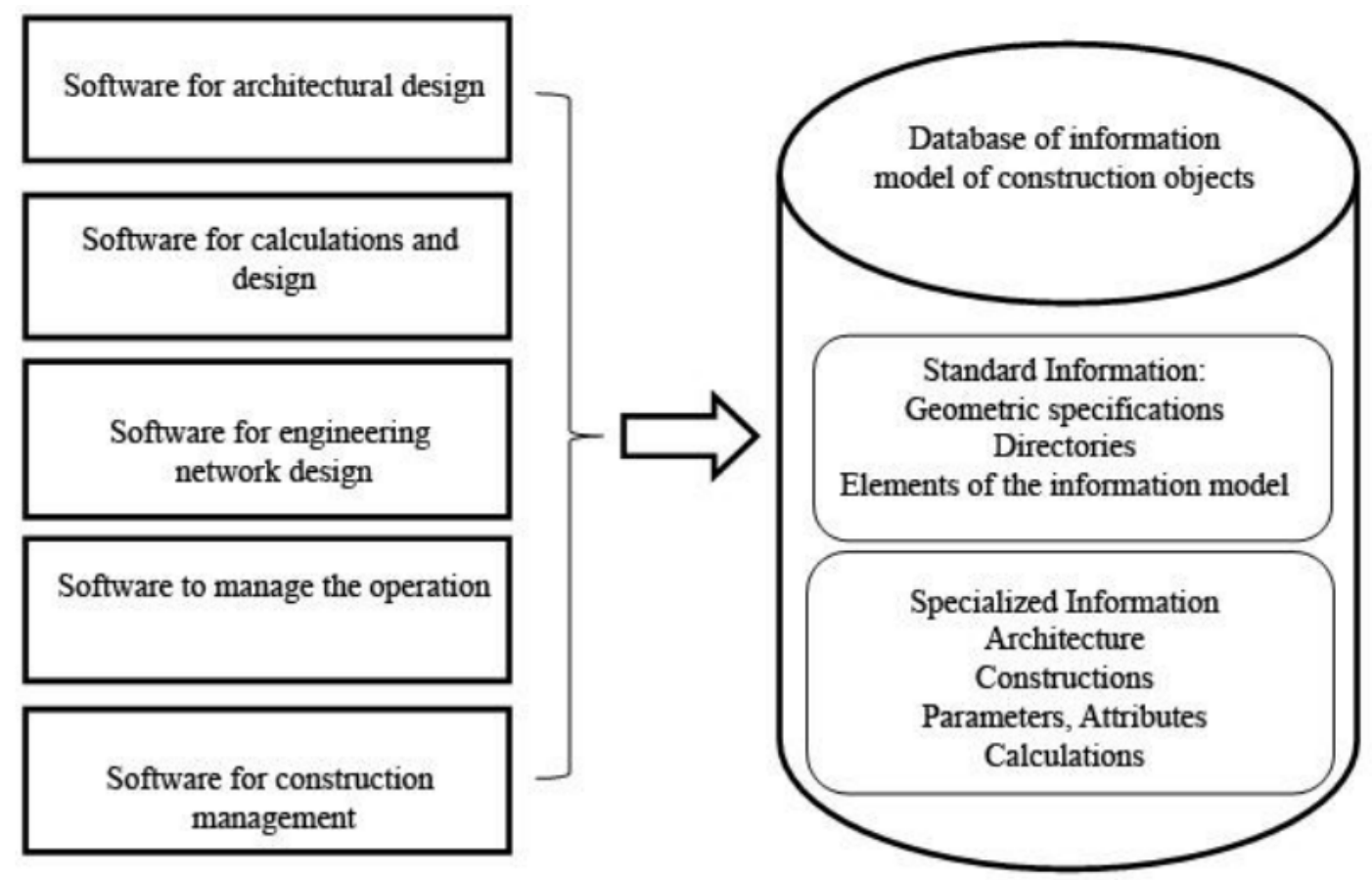

Figure 1 Conceptual model of the database of information model of construction objects

TABLE 1 CLASSIFICATION OF INFORMATION BY DESIGNATION OF THE SOFTWARE

\begin{tabular}{|c|c|c|}
\hline $\begin{array}{c}\text { Appointment of } \\
\text { software }\end{array}$ & Software & Integrating information \\
\hline $\begin{array}{c}\text { For architectural } \\
\text { design }\end{array}$ & $\begin{array}{c}\text { ArchiCAD, AutoCAD, Architectural } \\
\text { Desktop, Arcada, AllPlan, Revit, } \\
\text { MicroStation, SAPFIR }\end{array}$ & Geometry, topology, materials \\
\hline $\begin{array}{c}\text { For calculations } \\
\text { and design }\end{array}$ & LiraSapr, SCAD, Tekla Structure, Stark & $\begin{array}{c}\text { Geometry, materials, strength } \\
\text { characteristics, load } \\
\text { information, support fixing }\end{array}$ \\
\hline $\begin{array}{c}\text { For designing } \\
\text { engineering } \\
\text { networks and } \\
\text { communications }\end{array}$ & MagiCAD, RauWin, Allklima, Sankom, & $\begin{array}{c}\text { Geometry, materials, } \\
\text { information about the } \\
\text { properties of devices and } \\
\text { special information }\end{array}$ \\
\hline $\begin{array}{c}\text { To manage the } \\
\text { operation and } \\
\text { construction }\end{array}$ & ABK, AC-4, Building Manager, Spider & $\begin{array}{c}\text { Geometry, materials, volumes, } \\
\text { information about valuation, } \\
\text { suppliers, terms of work } \\
\text { execution }\end{array}$ \\
\hline
\end{tabular}

The table shows that some of the information is common to all software, the other part is unique. Although most of the software is using the same data formats for integration (for example, XML, PDF, DXF, etc.), the ability to transfer information in full and still not implemented. 
Therefore, the actual problems remain: creation (CAD files, text files, tables), management (control of versions, delimitation of access rights, preservation) and exchange (distribution, agreement, verification, editing) the single information on the project at different stages.

\section{MATHEMATICAL MODEL}

In practice, different methods of parameterizations are used, and there is still no generally accepted decision on their use. The most common are: tabular, hierarchical, and variation methods [10].

Table parameterizations consist of creating a table of parameters of the elementary elements. Creating a new instance of an element is done by selecting from a table.

In the process of hierarchical parameterizations (parameterizations on the basis of the history of constructions), 'construction trees' of all elements of the model are formed with their details (group of elements - an element).

Variation, or dimensional, parameterizations is based on the construction of sketches (with the overlay on the objects of the sketch of various parametric links) and the imposing by the user of restrictions in the form of a system of equations that determine the relationship between parameters.

The mathematical model of parametric design of a generalized information model of a building is determined by [14]: the set of components of Mi and the set of models of design solutions $\left\{\mathrm{D}_{\text {sol-1-1,..., }} \mathrm{D}_{\text {sol-n }}\right\}$.

$$
\mathrm{M}_{\mathrm{i}}=<\mathrm{S}, \mathrm{P}, \mathrm{V}_{\mathrm{r}}, \mathrm{C}, \mathrm{R}, \mathrm{P}_{\mathrm{r}}, \mathrm{cf}>\text {, }
$$

where $\mathrm{S}$ is a set of elements of the structure $\left\{\mathrm{s}_{1}, \ldots, \mathrm{s}_{\mathrm{n}}\right\}$;

$\mathrm{P}$ - set of parameters $\left\{\mathrm{p}_{1}, \ldots, \mathrm{p}_{\mathrm{n}}\right\}$;

$\mathrm{V}_{\mathrm{r}}$ is a set of parameter values $\left\{\mathrm{V}_{1 .}, \mathrm{V}_{\mathrm{n}}\right\}$, where $\mathrm{V}_{\mathrm{i}}=\left\{\mathrm{V}_{\mathrm{i}}, \ldots, \mathrm{V}_{\mathrm{in}}\right\}$ is a set of values for each parameter;

$\mathrm{C}$ - set of constraints on the values $\left\{\mathrm{c}_{1}, \ldots, \mathrm{c}_{\mathrm{n}}\right\}$;

$\mathrm{R}$ - set of requirements for the model $\left\{\mathrm{r}_{1}, \ldots, \mathrm{r}_{\mathrm{n}}\right\}$;

$\mathrm{P}_{\mathrm{r}}$ is a set of preferences $\left\{\mathrm{P}_{\mathrm{ri}}, \ldots, \mathrm{P}_{\mathrm{rj}}\right\}$;

$\mathrm{cf}$ is a global value function.

The element of the $s_{i}$ structure defines the primitive element of the design model. The pi parameter is the characteristic of the i-th element of the structure. Each parameter is associated with a range of values $\mathrm{V}_{i}$, predetermined by the set of values that is assigned to pi. There are $\mathrm{m}$ possible values for the parameter and $n$ parameters. The size of the design space is $\mathrm{N}=\mathrm{m}^{*} \mathrm{n}$. The values of functionally dependent parameters are uniquely determined by functional dependencies or requirements. Functionally independent parameters are called key, and their values are determined by degrees of freedom in the design process, i.e. the actual size of the design space $[12,13]$.

The process of generalizing the parameters obtained from different models consists in evaluating possible solutions (alternatives) and choosing the best of them according to the given criteria. The implementation of any solution option involves the emergence of some effects, analysis and evaluation of which, as a rule, for a few (vector) performance criteria completely characterize this option solution. In this case, it is necessary to solve the problem of decisionmaking that occurs when there are several alternative options for the desired result. In this case, you need to choose the best alternative in a certain sense. Decision-making is to build an adequate model for choosing the best alternative. 
Kateryna I. Kyivska, Svitlana V. Tsiutsiura, Mikola I. Tsiutsiura, Olena V. Kryvoruchko Andrii V. Yerukaiev and Vladyslav V. Hots

The multivariate, qualitative differences in parameters, the possible uncertainty of the model coupled with the uncertainty become an obstacle in obtaining an assessment of the quality of the model and lead to the consideration of general approaches to the concept of optimality, that is, the development and development of new methods in the theory of decision making for multicriteria fuzzy tasks.

Many decision-making tasks have such a characteristic feature: the model describing the set of permissible decisions is objective, but the quality of the decision is evaluated by many criteria. To choose the best option, a compromise between the estimates for the different parameters is required.

When many parameters appear, the task of choosing the best solution has the following features:

- the task is unique - there are no statistical data that can justify the correlation between different parameters;

- at the time of decision making there is basically no information that allows an objective assessment of the possible consequences of choosing one or another solution. But since the decision, one way or another, must be taken, the lack of information must be filled in. This can only be done by people based on their experience and intuition.

In the multicriteria tasks, the part of the information necessary for a complete and unambiguous determination of the requirements for a solution is fundamentally absent. The user can often identify the main variables, establish connections between them, and build an adequate model. But the relationship between parameters in general cannot be determined on the basis of objective information. Such problems are poorly structured, as there is a problem with the availability of objective information at the time of the decision. There are also problems in which only the list of basic parameters is known, but quantitative connections between them cannot be established, as there is no necessary information. Sometimes the change of the parameter in certain limits affects the solution obtained. In such cases, a structure that is defined as a set of relationships between parameters that is undefined and has certain collisions is called unstructured. Weak structured and/or unstructured problems are investigated within the framework of solutions of multi-criteria problems.

Problems of decision-making in risk conditions (stochastic problems) arise in cases where every decision taken $x \in L$ is associated with a set of cases of $m$ of possible results $S_{1}, \ldots, S_{n}$ with known probabilities $\mathrm{P}\left(\mathrm{S}_{\mathrm{j}} \mid \mathrm{x}_{\mathrm{i}}\right)$, that is, in these tasks do not have a clear connection between the alternatives and the result. When $P\left(S_{j} \mid x_{i}\right)=1$, the problem of decision-making in a risk and the deterministic problems of decision-making are identical [16].

To solve the problems of decision-making at risk, methods of the theory of stochastic programming, games, mass maintenance and other probability theories are widely used. Let $1_{\mathrm{ij}}$ $=f\left(S_{j} \mid x_{i}\right)$ be the utility function of the result $S_{j}$ when deciding xi and $P\left(S_{j i} \mid x_{i}\right)$ and $P\left(S_{j} \mid x_{i}\right)$ are conditional probabilities characterizing the transition of an object to the state $S_{j}$ using $x_{i}$, then the usefulness of each solution is presented as:

$$
u\left(x_{i}\right)=\sum_{i=1}^{m} f\left(W_{i}, x_{i}\right) P\left(W_{i} \mid x_{i}\right)
$$

In this case, the choice of solution is carried out according to the following rule, which ensures achievement of the maximum value of the expected utility:

$$
x=\arg \max \left\{u\left(x_{i}\right)\right\}
$$

The task of combining the parameters of construction objects obtained from different models in a generalized form is to choose the values of parameters in which an object will meet 
all the requirements that are advanced to it at different stages of modeling in solving specific problems (design calculation, formation of calendar schedules, creation of estimates, etc.) [17].

To do this, the output parameters must meet the constraints:

$$
y_{i}(g, x, q) \geq A_{i}, \quad y_{i}(g, x, q) \leq B_{i}, i=1, n
$$

where $y_{i}(g, x, q)$ - $\mathrm{i}$-th output parameter, which is some function of geometric parameters $\mathrm{g}=\left(\mathrm{g}_{1}, \ldots, \mathrm{g}_{\mathrm{t}}\right)$, internal parameters $\mathrm{x}=\left(\mathrm{x}_{1}, \ldots, \mathrm{x}_{\mathrm{m}}\right)$ and external parameters $\mathrm{q}=\left(\mathrm{q}_{1}, \ldots \mathrm{q}_{\mathrm{k}}\right)$; Ai and $\mathrm{Bi}$ are the limits of permissible changes of the initial output parameter described in the requirements.

As parameters that need to be optimized, internal parameters are selected that can be changed at this stage of the merger. In general, the task is written as follows: max $(F(g, x, q)), x \in D$, де $F(g, x, q)$ - target function and limiting function - nonlinear functions of controlled parameters, D - domain of permissible changes of internal parameters, which reflect the operating conditions of the system and the space of internal parameters. When optimizing, either the nominal value of external parameters, or those that describe the worst case, are selected.

Combining parameters from different models allows you to determine the operating modes of model elements and get information about possible deviations of parameters from the calculated data. After that, there is an opportunity to check the implementation of the requirements for the quality of operation, taking into account these deviations.

Deviations of parameters arise under the influence of the factors acting in the process of modeling, production, operation, and are of a random nature. Therefore, internal parameters must be considered as some random functions of time. Consequently, the conditions of the working state of the model can be satisfied only with a certain probability:

$$
P(t)=P\{X(t) \in D, \forall t \in[0, T]\}
$$

where $X(t)$ is the random process of changing internal parameters, $T$ is the given time of the system's operation. The selected nominal values of the parameters can be considered as components of the mathematical expectation vector of the random process $X(t)$ at the initial time $\mathrm{t}=0$, when $\mathrm{x}_{0}=\mathrm{M}[\mathrm{X}(0)]$.

The main problems that arise when solving the problem of combining the parameters of information model of construction objects taking into account the random variations of these parameters are connected with the high computational complexity of tasks of multivariate analysis, which in this case arise. At each step of optimization, there is a need for statistical analysis to obtain an estimation of the optimality criterion. In this case, on the basis of the static test method (Monte Carlo) [10], the system (model) under investigation is repeatedly calculated at various values of the parameters of the elements. The number of calculations $\mathrm{N}$, which is equal to the number of realizations of the random parameter vector, is determined from the condition of ensuring the required accuracy of the criterion evaluation. In order to ensure satisfactory accuracy of the assessment, it is necessary to periodically perform a complete calculation of the system. You can also use parallel computing methods to reduce the time and number of system calculations.

\section{PARAMETERIZATION OF ELEMENTS OF BUILDING OBJECTS}

The parameters of elements of the information model of building objects can be globally distributed to internal and external. Internal stores all information about the object and its elements, which can be obtained from different formats or software complexes, and is used to create the technological chain of the information model. External information includes information from directories (materials, volumes of norms), which makes no sense to keep in 
Kateryna I. Kyivska, Svitlana V. Tsiutsiura, Mikola I. Tsiutsiura, Olena V. Kryvoruchko Andrii V. Yerukaiev and Vladyslav V. Hots

the general database and unformalized information that cannot be processed under any circumstances.

Taking into account the specifics of creating a generalized information model of a building object, the main requirements for the model were formulated:

- The primary document is a $2 \mathrm{D}$ or 3D model;

- It is mandatory to fill out the data card for the elements of the model for the specification (name, designation, material, etc.);

- Models must be specified in a specific coordinate system and contain information about the size (estimated, depending on the scale and coordinate system or graphic).

Each element of a building object in a database stores a certain set of information, which is structured in the form of frames or relational databases (Fig. 2).

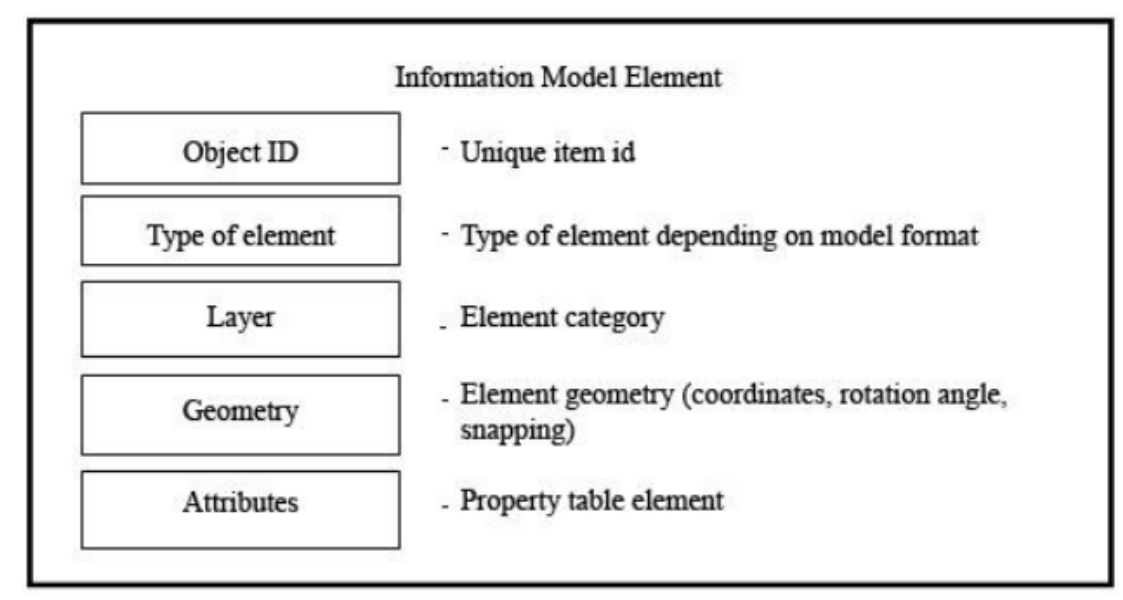

Figure.2 Information about the item in the database

Depending on the presentation format of the model, one and the same element can be represented using different types (Fig. 3). 


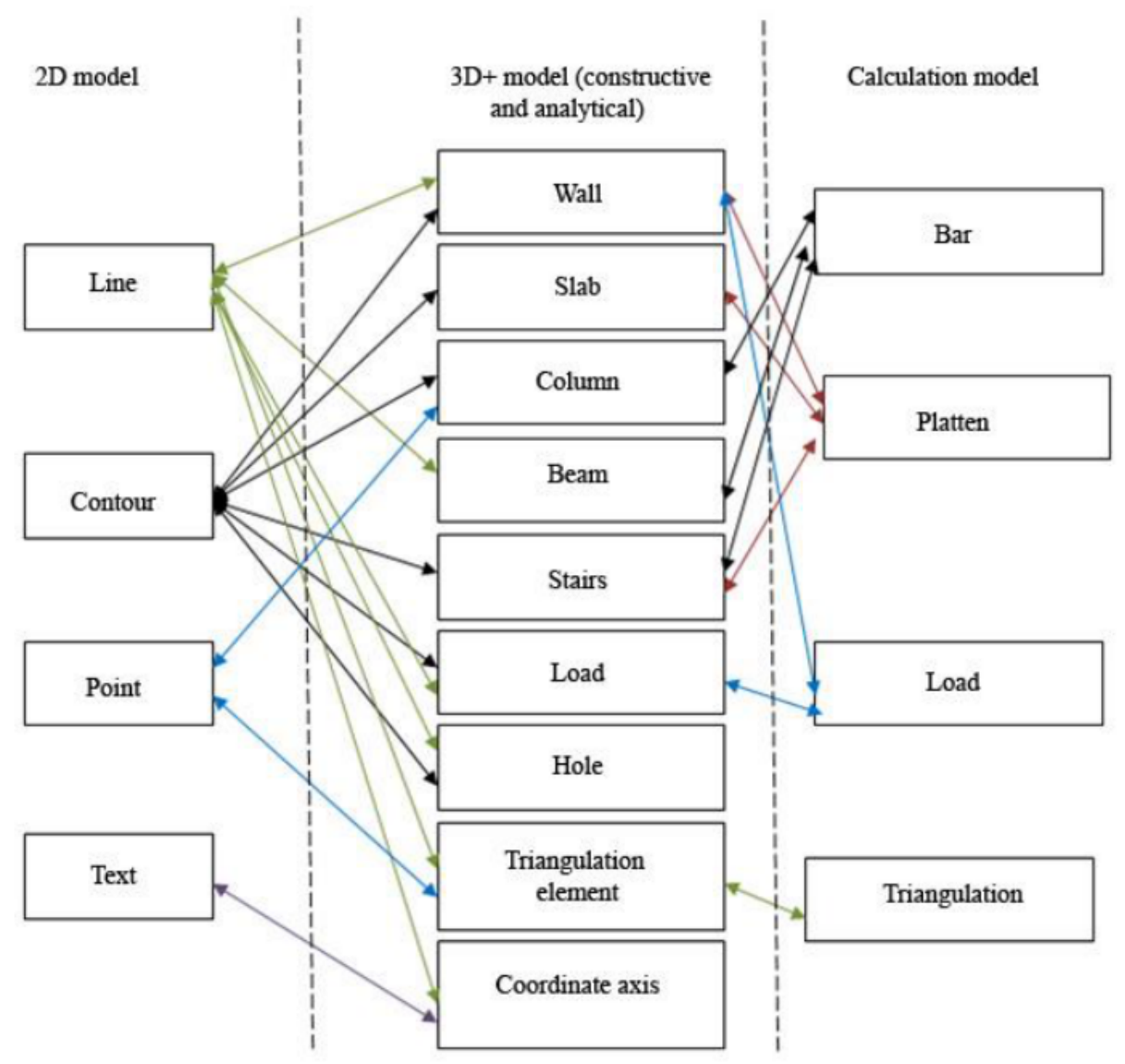

Figure.3 Types of elements in the format of presentation of models

Depending on the format of the presentation of the model, the elements will have a different set of parameters. So, for the 2D model, graphical parameters (coordinates, dimensions) are relevant, for 3D+ models - physical parameters of the constructive elements (material, section, mass, level of location, load on the element, mode of interaction with other elements: node connection, hinge connection, hard connection, and their means of processing: trimming, crossing, reaching, etc.), for the calculation model, the parameters of finite elements and nodes (boundary conditions, estimated coefficients, etc.).

\section{AN EXAMPLE OF THE RESULTS OF THE SUBSYSTEM INTEGRATION MODELS}

The technology for transmitting information from a two-dimensional drawing of a floor plan from AutoCAD to SAPFIR is presented in the following example.

Formed in AutoCAD floor plan (Fig. 4) we pass into the SAPFIR. Additionally, we create and fill the set of parameters needed to create a 3D model (Fig. 5). Perform recognition of the information obtained from the drawing to form a three-dimensional parametric model. As a result, on the basis of the two-dimensional drawing, we obtain a complete 3D model (Fig. 6), which can then be transferred to the settlement and/or other software complexes, to perform a robust calculation, to supplement the model with the results of the calculation in order to further formulate the working design documentation. 
Kateryna I. Kyivska, Svitlana V. Tsiutsiura, Mikola I. Tsiutsiura, Olena V. Kryvoruchko Andrii V. Yerukaiev and Vladyslav V. Hots

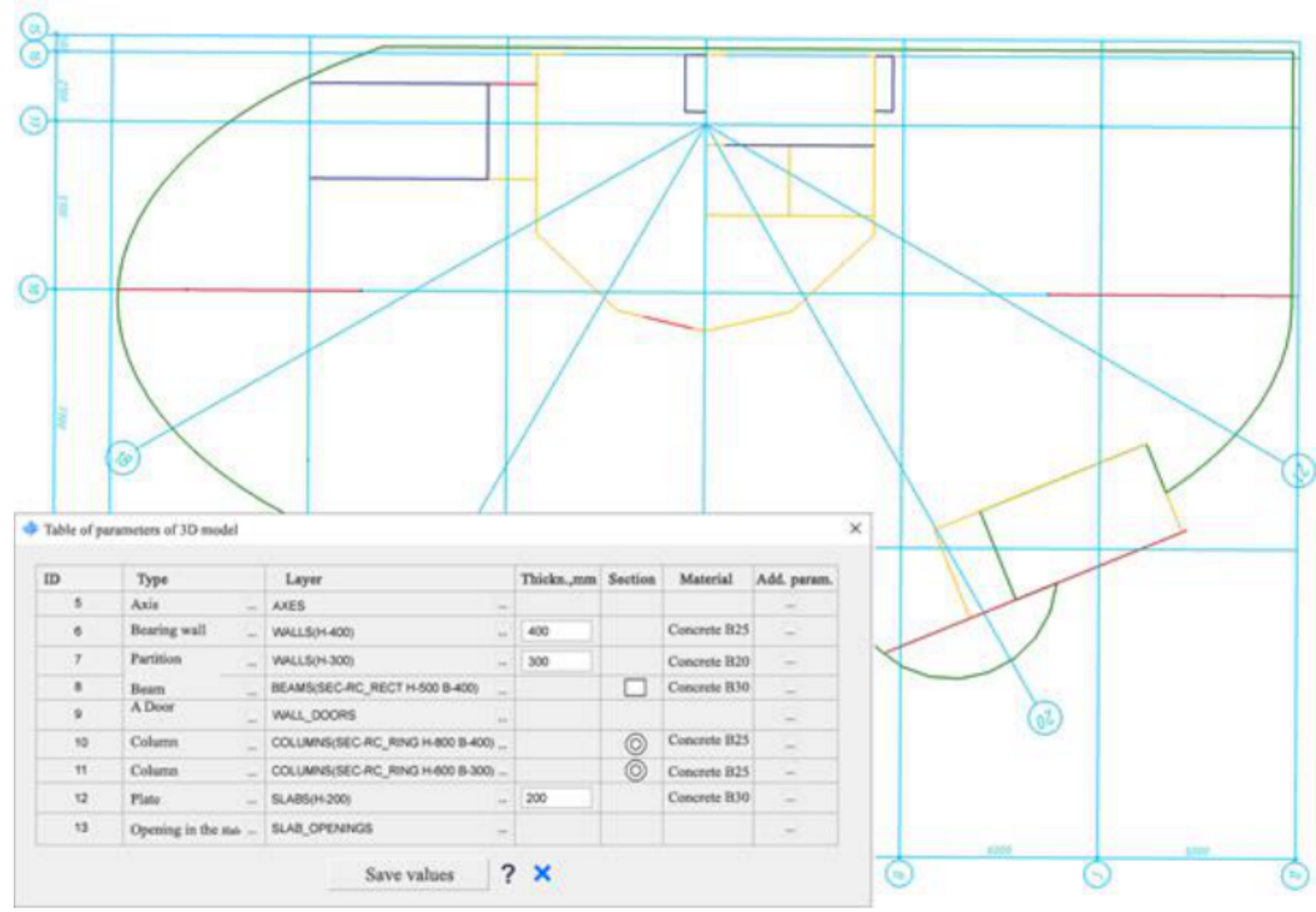

Figure.4. Graphic model of a building object, integrated with the program AutoCAD

\begin{tabular}{|c|c|c|c|c|c|c|c|}
\hline \multicolumn{8}{|c|}{$\oplus$ Table of parameters of 3D model } \\
\hline ID & Type & \multicolumn{2}{|l|}{ Layer } & Thickn.,mm & Section & Material & Add. param. \\
\hline 5 & Axis & AXES & - & & & & -- \\
\hline 6 & Bearing wall & Waus $(\mathrm{H}-400)$ & - & 400 & & Concrete B25 & ... \\
\hline 7 & Partition & WALLS(H-300) & - & 300 & & Concrete B20 & -. \\
\hline 8 & Beam & BEAMS(SEC_RC_RECT H-500 B-400) & ... & & $\square$ & Concrete B30 & ... \\
\hline 9 & A Door & \multicolumn{2}{|l|}{ WALL_DOORS } & & & & -. \\
\hline 10 & Column & \multicolumn{2}{|l|}{ COLUMNS(SEC-RC_RING H-800 B-400) ... } & & (2) & Concrete B25 & ... \\
\hline 11 & Column & \multicolumn{2}{|l|}{ COLUMNS(SEC-RC_RING H-600 B-300) ... } & & (a) & Concrete B25 & .. \\
\hline 12 & Plate & SLABS(H-200) & - & 200 & & Concrete B30 & - \\
\hline \multirow[t]{2}{*}{13} & Opening in the sles ... & SLAB_OPENINGS & - & & & & - \\
\hline & & Save values & ? & $\mathbf{x}$ & & & \\
\hline
\end{tabular}

Figure.5. Parameters of the 3D model in the parametric SAPFIR database

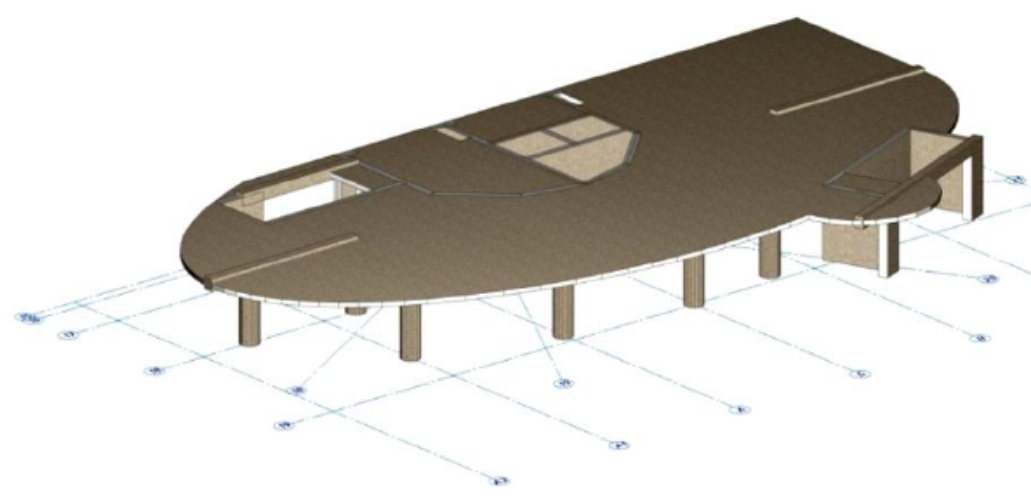

Figure.6. 3D model in SAPFIR 
An example demonstrates the ability to create a database object, based on a graphical element in the drawing, and assign it a certain set of properties. When changing the parameters of an object, its graphic characteristics remain unchanged. In addition, the change of the set of parameters occurs depending on the chosen mode of presentation of the model.

\section{FINDINGS}

The feature of the concept of a single information computer model of a building object is the use of dynamically updated tables, which gives the user the opportunity to work in the usual software tools and one time to create a model that is subsequently updated, supplemented and modified depending on user requests.

The only graphic-information model of a building is: an agreed graphic and descriptive data bank, a project database; the only source of information for all parts and stages of the project; information is obtained from the model on the principle of necessity and adequacy; the only development object for all project participants; data accumulation occurs in parallel or sequentially. At any time, at the request of the user, the graphic information can be read from the model and published in the correct form: drawing plans, facades, types, sections, nodes and details, assembly schemes. Quantitative information is obtained from the same model, which automatically generates specification tables, information, reports, and estimates. Moreover, the attributive information is also read from graphic objects or transmitted through the connection of these objects with databases.

Integration of information model of building objects with systems of calculation, analysis and design of structures provides continuity between physical, analytical and calculation models of a building.

\section{REFERENCES}

[1] Johnny W., Xiangyu W., Heng Li, Greg Chan, Haijiang L. A review of cloud-based BIM technology in the construction sector // Journal of Information Technology in Construction, ITcon, Vol. 19, 2014 - PP.281-291.

[2] Chapman C.B., Pinfold M. The application of a knowledge-based engineering approach to the rapid desing and analysis of an automotive structure, Cambridge: Elsevier, Advances in Engineering Software, 2001, Vol. 25.

[3] Gorodetsky A.S., Barabash M.S., Sudak V.S. Integrated design and construction management systems using a fully functional building information model (BIM). Foreign and domestic experience, development prospects // Problems of urban environment development: Scientific and technical collection, Issue 2 (12), Kyiv, 2014 - P.499.

[4] Barabash M.S., Boychenko V.V., Palienko O.I. Information technology integration based software SAPFIR: Monograph, Kyiv, 2012. - P.485.

[5] Muto M. Study on application BIM technologies for building certification on technical standards conformity // CIB Tokyo IDDS\&BIM One day Seminar, 2013. - PP.4-6.

[6] Shuichi F. Concurrent Engineering in a New Perspective: Heading for Seamless Engineering. Concurrent Engineering Approaches for Sustainable Product Development in a Multi-Disciplinary Environment, London: Springer Verlag, 2013. - PP.15-26.

[7] Motta E., Zdrahal Z. Parametric Design Problem Solving // Presented at the 10th Knowledge Acquisition for Knowledge-Based Systems Workshop, Banff Canada, November 1996.

[8] http://ksi.cpsc.ucalgary.ca/KAW/KAW96/motta/pardes-banff.html

[9] Kievskaya E.I., Barabash M.S. Principles of parametric modeling of building objects // Modern construction and architecture, Issue 1, Yekaterinburg, 2016. - PP.16-22. 
Kateryna I. Kyivska, Svitlana V. Tsiutsiura, Mikola I. Tsiutsiura, Olena V. Kryvoruchko Andrii V. Yerukaiev and Vladyslav V. Hots

[10] Afonichkin A.I., Mikhaylenko D.G. Management solutions in economic systems. Textbook for universities, St. Petersburg, 2009. - P.480.

[11] Afanasyev A.A., Matveev E.P. Reconstruction of residential buildings. Part I // Technologies for the reconstruction of residential buildings and buildings, Moscow, 2008. - PP.46-52.

[12] Saushev A.V. Structure, method and algorithms for optimal parametric synthesis of dynamic systems // Proceedings of the International Symposium "Reliability and Quality", Vol.1, 2013. - PP.124-128.

[13] Eastman C., Teicholz P., Sacks R., Liston K. BIM Handbook, New Jersey: John Wiley \& Sons, 2008. - P.204.

[14] Kuhn, Olivier, Liese, Harald, Stjepandic, Josip Engineering Optimisation by Means of Knowledge Sharing and Reuse // The International Federation for Information Processing, Vol. 277, 2008. - PP.95-106.

[15] Foley D.J., Feiner S.K., Hughes J.F. Computer graphics. Principles and practice. N.Y.: Addisson-Westey, 1991. - P.344.

[16] Greeen P., Rosemann M. Integrated process modeling: An ontological evaluation // Information Systems, Cambridge: ELSEVIER, Vol. 25, 2000. - PP.112-115.

[17] Isikdag U., Aouad G., Underwood J., Wu S. Building Information Models: a review on storage and exchange mechanisms. - in: D. Rebolj (Ed.), Proceedings of 24th W78 Conference: Bringing ITC knowledge to work, Maribor, 2007. - PP.135-144.

[18] Jardim-Goncalves R., Grilo A. SOA4BIM: putting the building and construction industry in the Single European Information Space // Automation in Construction, Vol. 19 (4), 2010. - PP.388-397.

[19] Jariri F., Zegordi S.H. Quality Function Deployment, Value Engineering and Target Costing, an Integrated Framework in Design Cost Management: A Mathematical Programming Approach // Sharif: Sharif University of Technology, Vol. 3, Scientia Iranica, 2008. - P.15.

[20] Nitin H. Ambhore, Shyamsundar D. Hivarale and Dr. D. R. Pangavhane, A Comparative Study of Parametric Models of Magnetorheological Fluid Suspension Dampers, International Journal of Mechanical Engineering and Technology (IJMET), Volume 4, Issue 1, January- February (2013), pp. 222-232.

[21] Vikas Gandhe and Dr. Peeyush Chowdhary, Parametric Studies of Truss Bridges for Economic Considerations. International Journal of Civil Engineering and Technology, 7(4), 2016, pp.285-295.

[22] Eldo Simon and Dr. M. Sirajuddin, Parametric Study of Stand-Off Distance on a Bridge Under Blast Loading. International Journal of Advanced Research in Engineering and Technology, 8(2), 2017, pp 01-07. 